\title{
Kripto Para ve Tipleri, Bitcoin Olgusu ve Muhasebesi
}

\author{
DOI: $10.26466 /$ opus. 585051 \\ * \\ Mehmet Can Yumusaker*
}

* Osmaniye Korkut Ata Üniversitesi , İktisadi İdari Birimler Fakültesi /Osmaniye/Türkiye E-Posta: canyumsaker@hotmail.com

ORCID: $\underline{0000-0001-5726-9340}$

Öz

Çoğu ülkede Sanal para, bitcoin gibi isimlerle adını duyuran kripto paralarn işlem hacimleri üst düzey boyutlara ulaştı̆̆ görülmüştür. Hatta günümüzde birçok firma ödemelerini iş çi ücretlerini kripto paralarla yapmaktadır.Bu paraların bir çok avantajının olması yanında bir takım dezavantajlarının olduğu görülmüştür. Kripto paralar hukuki anlamda kabul görmüş olmasa da yüksek kar getiri oranı, kolay transfer edilmesi, işlem çok az olması gibi sebeplerle işletmeleri hayran bırakan bir yatırım aracına dönüştürmüştür. Günümüzde Ticari işletmeler kripto paralarla tediyeişlemleri borçlanma işlemleri veya tahsilatlarm gerçekleştirebilmekte olup ayrıca kur getirisinden extra yararlanmak sebebiyle kripto paralara çok sık yatırım yaptıkları görülmektedir. Ayrica bu paralarn piyasada bir çok modeli olması ve bu paraların kendine has bir borsası vardır. Very madenciliği yapılmasada aynı borsadaki gibi arz talep dengesine bağlı olarak kar getirisi elde etmek mümkündür. Bu çalışmanın amacı sanal paralar ve bitcoin özelinde tüm kripto paraların nasıl çalıştığı ve bu paraların özellikleri hakkında bilgi verip Türkiye'de Bitcoin ile yapılan ticari işlemlerinin muhasebeleştirilmesi hakkında değerlendirmelerde bulunmaktır.

Anahtar Kelimeler: Kriptografi, Kripto Para Birimleri, Bitcoin, Kripto Para Muhasebesi 


\title{
Crypto Money and Types, Bitcoin Case and Accounting
}

\begin{abstract}
In most countries, the trading volumes of cryptocurrencies that announce their name with names such as virtual currencies, Bitcoin, have been seen as high-level dimensions. In fact, many companies nowadays pay their business fees with crypto coins. These coins have a lot of advantages, as well as a number of disadvantages have been seen. Although cryptocurrencies have not been legally accepted, the high profit rate has been transformed into an investment tool that admires businesses for reasons such as easy transfer and minimal processing. Nowadays, commercial enterprises are able to carry out borrowing transactions or collections of cryptocurrencies, and they also invest very often in cryptocurrencies due to extra benefit from the return of the exchange. In addition, these coins have a lot of models in the market and these coins have a unique exchange. It is possible to achieve profit return depending on the balance of supply demand as well as on the same stock exchange at the Very Mining construction table. The aim of this study is to assess how all cryptocurrencies are working in virtual currencies and Bitcoin and to provide information about the characteristics of these currencies and to evaluate the accounting of trade transactions with Bitcoin in Turkey.
\end{abstract}

Keywords: Crypto currencies, bitcoin, crypto currencies accounting 


\section{Giriş}

İnternetin yaygınlaşması ve kullanılan teknolojik alt yapının gelişmesi ve sonrasinda elektronik ticaret uygulamalarına olan talebin artması ile birlikte çok çeşitli elektronik para birimi yaratma girişimleri yapılmış fakat ilk denemeler başarılı olmamıştır. Oluşturulmak istenen paranın sadece "veriler" den oluşmasından ve oluşumun kontrol mekanizması olmamasından kaynaklı olarak kişiler aynı "veriler" ile birden fazla ticari faaliyet yapabilmiş ve bu durumun yarattığı problemlerin engellenmesi adına sanal para birimi oluşumu engellenmiştir. Çift veya çoklu harcamaların önüne geçebilmek için sanal paranın harcanıp tüketildiğini kontrol edebilecek bir merkezi sistem merkezi beyin arayışlarına gidilmiş ve sonuç olarak "kriptoloji teknolojisi" kullanılmış ve bu soruna bir nevi çözüm getirilmiştir. Bir hesaptan bir hesaba aktarılması birtakım şifreler aracılığıyla gerçekleşmekte ve bu durum merkez bankaları tarafından kontrol edilemeyen para birimlerinin son dönemlerde önemli bir şekilde gündemde olması kripto para yaratma için yatırımlar yapan kişi ve kurumların sayısında artış görülmektedir. Ülkelerin bu sorunu düzenlemek için bir takım sınırlamalar önlemler alması şart hale gelmiştir. Bu durum ülkelerde farklı şekillerde sonuçlanmış olup kimi devletlerr bu para birimini tanımak anlamak ve düzenleme yapmaya çalışmış kimi devletler ise hiç yürürlüğe sokmadan direk olarak redetmiştir. Bu para birimi çeşitli isimlerde tanınmaktadır bunlar Sanal para, kripto para e-para digital para gibi isimler ile anılmaktadır. Bu para birimini öne çıkaran nedenler ise geleneksel ödeme araçlarından hızlı işlem yapısına sahip olması devlet banka ya da çeşitli organizasyonlar tarafından kontrol edilememesi gibi nedenler yer almaktadır. Kripto parayı kullanıcılar değerli madenlere benzetmektedirler. Bu çalışmada adı anılmış para birimlerine kripto para birimleri denilmiş olup ayrıca bitcoin birimi ayrıntılı olmak üzere, diğer para birimleri ve araçlar kısaca açıklanmış olup sonrasında ise bitcoin birimini kullanan firmaların işletmelerin bu para birimiyle yaptığ takası nasıl muhasebeleştireceği konusuna değinilmiştir. 


\section{Kripto Para Birimleri Hakkında}

Para kavramı dünden bugüne hayatımızda yer almış olan insanların yaşam standartlarına etki eden en önemli buluşlar arasında kendini göstermiştir. Özellikle ticaretin alış verişin vazgeçilmez araçlarından birisi olmuştur. Paranın işlevleri ve etkilerinin yanı sıra bir mübadele aracı bir eşya ya da değer standartı olmuş hatta banka kredileri için rezerv veya saklama aracı sayılmıştır (Murad 1943). Para bir nevi satınalma aracıdır. Ticaret hayatında zaman veya emek gibi argümanları azatmakta olduğu görülmektedir. İnsanların birikim yapmasını özendirecek bir yani tüketim yapmasını azaltacak araçların başında gelmektedir. Paranın başka bir özelliğide değer kavramını maddeleştirerek fiyat karşılatırması yapılmasına olanak vermesidir. Kayıt alma konusunda para birimi kullanımı bu eylemi yapmayı kolaylaştırmaktadır. (The Federal Reserve Bank of Philadelphia, 2013).

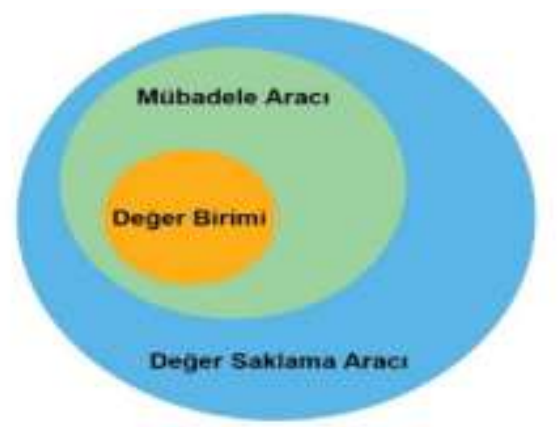

Şekil 1. Para Fonksiyonlarının Hiyerarşisi

Bir varlığın para olarak olarak sıfatlandırılması için taşınabilir, dayanaklı, bölünebilir, herkes tarafından kabullenilmiş olmalı ve sonsuz sayıda olmamalıdır (Clayton, 2001).

Kriptopra ise bir takım özel şifreleme methodlarıla korunan matematik temelli bir algoritması olan belli bir merkezi bulunmayan göndereni belli olmayan dağıtımı için bir çeşit dijital imza ve anahtarlara ihtiyaç duyan dönüştürülebilir parabirimini ifade etmektedir. Şifrelenmiş paralara ait hesapların güvenliği, sağlaması veya doğruluğu ise birbirlerinden haberi olmayan kişiler tarafından oluşturulmuş bir network ağ tarafından sağlanmakta olduğu görülmüştür. Bu network ağını koruyan 
biribirlerine karşı itimatı olmayan kişiler üretilmiş olan her bir şifrelenmiş paradan kendilerine systemin belirlediği ölçüde bir ücret tahsis etmektedirler (FATF, 2014).

\section{Blockchain Teknolojisi}

$\mathrm{Bu}$ kavram oluşturulmuş bir iş ağındaki yapılan işlemlerin kayıt altına alınmasını takip edilmesini kolaylaştıran ortak ve dağıtılmış olan bir hesap defteri aracıdır. Bu araç maddi bir değeri var kabul edilmiş her şeyi takip edebilir ve bir alış verişe konu olabilir. Bu yöntemle ticaret riskleri azaltılmış olur (Gupta, 2017).

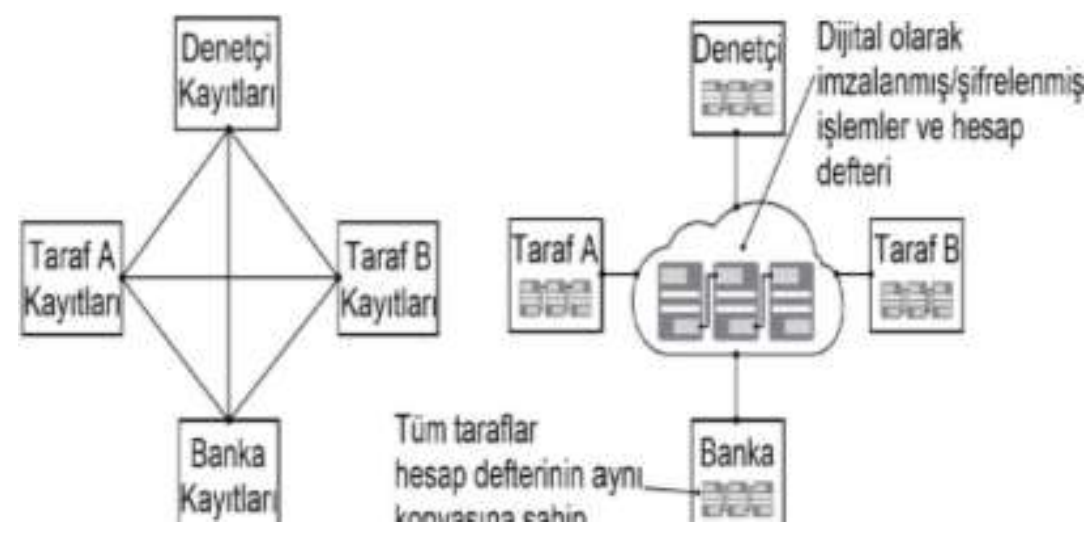

Şekil 3.Blok Zincir teknolojisi Şeması

Blockchain teknolojisinin temelleri kullanıcılar tarafından mutabakat sağlaması, kullanıcıların varlığın menşeyini bilmeleri yapılan işlemlerin değişmez ve kesinlik taşıması gibi kavramlar üzerine bina edilmiştir.

\section{Kripto Para Tipleri}

\section{Bitcoin Nedir}

Bitcoin, (sembolü, simgesi: B, kısaltma: BTC) dış satımı ve güvenilirliği bir kurum kuruluş tarafından gerçekleştirilmeyen kripto para birimidir. (Sönmez, 2014, s.8). Bitcoin, dijital para sistemlerinin very madenciliğin 
temelini oluşturan para birimlerinin birleşimidir. $\mathrm{Bu}$ ağ sistemdeki kullanıcılar arasındaki değiş tokuşun sağlanması için kullanılan araca bitcoin adı verilmiştir. (Antonopoulos, 2014, s.1). Birtakım ekonomistler, bitcoinin, yukarda sayılmış olan para özelliklerinin bitcoinde olduğunu savunmuştur. (Bitcoin markette, 2014). Fakat bitcoinin paranın kontrol mekanizmasının olmayışı yani merkez bankası tarafından kontrol edilemiyor olması ve bunun yanında basılı bir banknot ya da materyal olmadığ için para olarak sayılmamıştır. Bitcoin, diğer para birimleri gibi birtakım ticaret alışveriş, tasarruf veya yatırım amaçlı kullanılabilen elektronik ortamda üretilebilen kripto edilmiş yönetilebilen bir para birimidir.

\section{Bitcoinin Özellikleri ve İşleyişi}

Bitcoinin diğer para birimlerinden farkları şu şekilde anlatılabilir (howbitcoinworks, 2015): a. Bitcoin, merkezi bir otoriteye bağlı değildir ve P2P3 teknolojisini kullanır. b. Bitcoin para birimi tamamen dijitaldir. c. Bitcoin para biriminin 21 milyonluk üst limiti vardır. d. Bitcoin karmaşık yapılı bir üründür. e. Bitcoin para biriminin sınırlı bir kullanım ağı vardır. $f$. Bitcoin para birimi sigortalanmaz. Bitcoin para birimi, 2008 yılında Satoshi Nakamoto tarafından kapalı olan bir email grubuna yollanmış bir email ile lansmanı yapılmış olup istekli kullanıcılara sunulmuştur. 2009 yılında bitcoin para birimi yazılımı kullanıcıların hizmetine sunulmuştur. Paranın takaslanması sürecinde paranın sahibi, bir sonraki kişiye parayı gönderirken kendi kripto yani dijital imzasıyla bir önceki işlemin hesap özetini ve bir sonraki kullanıcının açı anahtarını imzalamaktadır ve bu imzayı bitcoinin sonuna gelecek şekilde eklemektedir bu iş için blokzincir teknolojisi kullanılmaktadır (bitcoin-makale, 2014). Bitcoin sistemde merkezi bir yapisı yoktur sadece internet ortamında mevcuttur. Dolayısıyla diğer ödeme yöntemlerinde görüldüğü gibi satıcıyı ya da alıcıyı ilgilendiren bir çok maliyet yok denecek kadar azdır. (litecoin nedir, 2013). Maliyet olarak sadece çok küçük komisyonlar vardır. Ayrıca, sistemin sahip olduğu kripto teknolojisi blok zincir sayesinde tüm işlemlerin güvenlik ve gizliliği sağlanmaktadır (sanal para birimleri, 2014). Tüm bu sinerjik faydalar bitcoin para biriminin tercih edilme oranını artırmıştır. Bunların yanısıra para arzının yaratılması işlemi herkesin gözü önünde ve açık tarafsız kurallarla gerçekleşmektedir (litecoin nedir, 2013). Bitcoin 
sanal ortamda bir bilgisayar network sistemine dâhil edilen kullanıcılar arasında, istenildiği gibi transfer edilebilmektedir (gerçek para bitcoin, 2015). Bitcoin, kendisini bir para birimi olarak kabul eden her tür yerde kullanılabilmektedir. Bitcoini kullanabilmek ilk başta bitcoin cüzdanı (bitcoinlerin saklandığı adresler bir çeşit pörtföy) oluşturmak lazım gelmektedir. Bitcoin finansal araç cüzdanı açık ve gizli anahtarı tutan koruyan bir dosyadır bu cüzdan, bilgisayara indirilen bir yazılım ile oluşturulabileceği gibi web tabanlı olarak oluşturulan servisler (Blockchain, Flexcoin, My Wallet.) kullanarak da yapılabilmektedir. Sonuçta bireye özel bir adres üretilmekte ve bitcoin para birimi transferi bu adres ile yapılmaktadır Bu adresler internet ağı üzerinden siteler ile, kişisel bilgisayarlarda veya kağıt olarak saklanabilmektedir. Bitcoin para birimi cüzdanının en iyi saklanma çeşidinin kağıt ortamı olduğu belirtilmektedir. Gönderimi yapacak olan kişi, bu adresi transfer aşamasında alıcı kısmına eklemekte ve birey kişisel şifresi ile onay verdikten sonraki süreçte bütün Bitcoin kullanıcılarının görmesi amacıyla yayınlayarak alıcıya gönderme işlemini hayata geçirmiş olur. Aynı bitcoini tekrar kullanmak için çok fazla bilgisayar gücüne ihtiyacı vardır. Kısaca bu işlemin gerçekleşmesi çok olası değildir. Çünkü Bitcoin'de blokzincir yani her yapılan süreç işlemler aşamalı olarak Bitcoin içine işlenmetedir. Sadece veride değişiklik yapmak isteyen kullanıcı, önceki işlem yapan bitcoin sahibinin kullanıcı hesabına girip bilgilerde değişiklik yapması gerekmektedir ve yazılım kullanıcılarının kimliklerinin gizli olması bunu imkansız hale getirmektedir. Kullanıcının burada yapması gereken, kendisine özel olan verilen kişisel şifresini korumasıdır (Acar, 2013). Bitcoin, yapılan ödeme veya transferlerin doğrulanması için açı anahtarlı şifreleme, noktadan-noktaya network bağlantısı ve dijital imza gibi çeşitli teknolojiler kullanır. Bitcoinler yukarıda bahsedildiği gibi ödeme veya transferi yapan adresten alıcıya ait adrese imzalanarak gönderilir. Her kullanıcı ilgili çok sayıda adrese sahip olabilmektedir. Her işlemin duyusu yapılır ve blok zincirinde yerini alır. Her bir işlem ortalama bir veya iki saat içinde, blok zincirini artırmaya devam eden büyük işleme gücü tarafından o anda kilitlenmiş olur. Bitcoin teknolojileri kullanarak, herkesin erişebileceği hızlı ve son derece güvenilir olan bir ödeme ağı sağlamaktadır (http://bitcoin-tr.com/). Bitcoinler, ücretsiz olarak sunulan bitcoin 
madenci yazılımını kullanan kişiler tarafından bitcoin ağı üzerinden belirlenmiş algoritmaların işletilmesi sonucunda üretilebilmektedir (Yalçın ve Gürbüz, 2015). Yapılan bu işeleme veri madenciliği denmesinini nedeni altın madenciliğine benzetilmesidir. Rezervin giderek azalması talebin artması değerini yükseltmektedir bilindiği gibi üst sınırı 21 milyondur (litecoin nedir, 2013). Yani Bitcoin veri madencilerinin üretebileceği maksimum bitcoin sayısı, bitcoin uygulamasında 21 milyon dolarla sınırlandırılmıştır (dijital parayı altına tercih eden ekonomi, 2015). Üretilebilecek Bitcoin miktarı, Bitcoin yazılımının beynini oluşturan bir algoritma beyin tarafından, belirli bir zorluk derecesine sahip bazı matematiksel problemlerin çözülebilmesiyle hesaplanmaktadır. Süreç çok karmaşık olduğundan hesaplamalar için ihtiyaç görülen bilgisayar gücü de çok fazla olmaktadır. Bu güç gereksiniminin sadece normal birkaç bilgisayarla karşılanması mümkün olmamaktadır. Bu gücün karşılanması gereken super bilgisayar gücü P2P (Peer to Peer) ağ içi network sistemi kullanrak kullanıcıların aynı ağ ortamına dahil edilmesiyle çözülmüştür. Eğer Bu ağdaki bir bilgisayar zor matemetik probleminin çözümüne yardımcı olmuşsa bu durumdan 25 bitcoin hediye almaktadır (gerçek para bitcoin, 2015). Türkiyede bir çok yerli firma ödemelerini bitcoin ile ödeyip alcakların bitcoin ile tahsil etmeyi Kabul etmektedir. Bunun yanı sıra bazı firmalar ise işçilerinin maaşını bitcoin ile ödemekte olduğu görülmektedir. Genel olarak bitcoin sisteminin siber saldırılara açı olması, yasalara uygun olmayan karanlık işlerde kullanılması dahi giderek yaygınlaşmasının önüne geçememiştir. Bitcoinle ilgili oluşan rakamlar da bitcoin kullanımının artığını doğrular niteliktedir. Bitcoinin piyasa değeri Temmuz 2014 itibarıla 7 milyar \$' a, işlem sayısı ise günlük olarak yaklaşık 70,000 adede ulaşmıştır (Sönmez, 2014, s.2). 14.Şubat.2019 itibariyle 13,926,425 adet bitcoin dolaşımda bulunmakta ve $1 \mathrm{BTC}=3601 \$^{\prime}$ dir. 14 Şubat 2019 itibariyle piyasa değeri $\$ 63,48 B^{\prime}$ dir. Bitcoin sisteminde merkezi bir otorite olmadığı belirtilmesine rağmen; bankaların bitcoin sürecine katılmamaları imkansız olasığılı taşımaktadır. Bitcoinin günlük hayatta kullanımı için yürürlükte olan tl euro gibi para birimlerine dönüştürülmesi gerekmektedir ve bu dönüşümde ortaya çıkan paranın saklanması için piyasa bankaları devreye girmektedir. Fakat bankaların, kendilerine yatırılmış olan parayı ve bu para hakkında bilgi sahibi olması zorunluluğu vardır. Amerika'da, bankaların para takibinin olmaması ve 
oluşan riskden dolayı Bitcoin ile çalışan firmaların hesaplarını kapatmış olduğu görülmektedir. Bu nedenle bu tür firmalar mevduatlarını kendi kasalarında saklamak zorunda kalmışlardır. Birçok banka, Bitcoin para birimi işlemlerini özel olarak izlemektedir (Acar, 2013). Şekil 2.4 de yukarda anlatılan bitcoinin şifrenlemesi özel anhatların nasıl oluşturulduğu ve pörtföy işlemlerinin nasıl yapıldığı simgesel ifadelerle anlatılmaya çalışılmıştır.

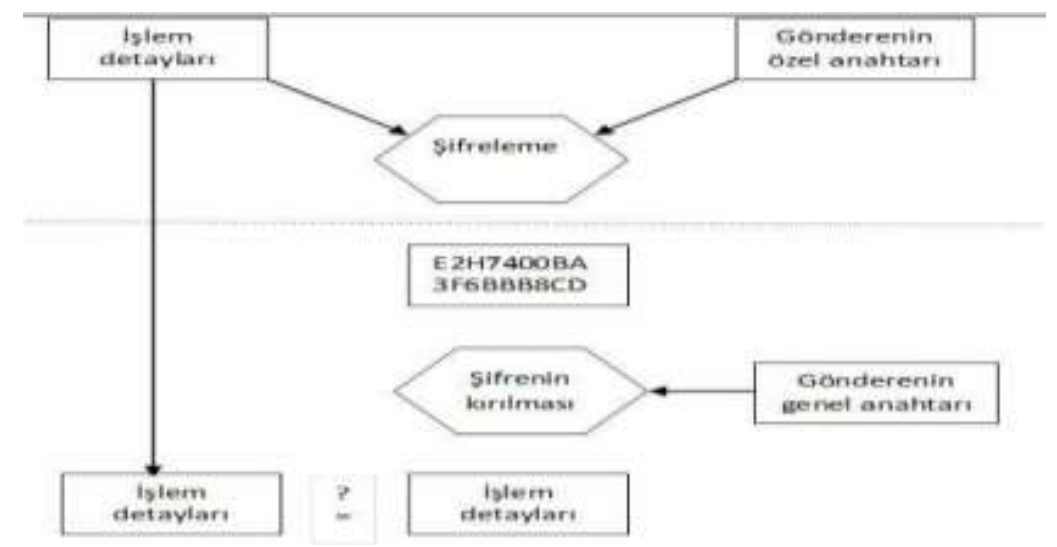

Şekil 3. Dijital İmzalar(Ali vd., 2014a)

\section{Bitcoin Madenciliği}

Kripto paraların transferi bilindiği gibi blok zincir dediğimiz bir teknoloji ile gerçekleşmektedir. Yapılan her işlem blok zincir tarafından kayıt edilmektedir. Yapılan işlemler defteri kebir gibi görev yapan blok zincir tarafından özetlenmekte hatta raporlanmaktadır. Elde edilen bilgilere (hash) denmektedir. Bitcoin madenciliği yapmak isteyenler bu blokları oluşturup işlemlerin gerçekleşmesini sağlamaktadırlar. Olay için uyulması gereken bir dizi protokol vardır. Bu kurallar nakamato tarafından oluşturulan makalede net bir şekilde belirtilmiştir. Madencilik belli yazılım programları yüksek güce sahip güçlü makineler ya da p2p teknoloji ağı kurularak yapılabileceği açıklanmıştır. Madenciliğin amacı blok zincir tarafından oluşturulan blokları bulabilmektir. Her bulunan blok için kullanıcı belli bir ücret kazanmaktadır. Sistem arz dengesini 
sağlamak amaciyla 210000 blok tamamlanınca madencilerin kazanacakları ücreti \%50 oranında azaltıp blok bulma zorluğunu artırmaktadır. Bundan dolayı arz belli bir orandan azalan ivmeyle artmaktadır. Bunların yanı sıra sistem 21 Milyon BTC olacak şekilde tasarlanmıştır (Ateş, 2016). İlk başlarda bu iş için daha az maliyet ve daha az bilgisayar gücü gerekliyken şimdilerde ise bu sistem değişmiş maliyetler ve bilgisayar gücü isteği artmıştır (How Bitcoin mining works, 2017). Günümüzde ise bu işlemler için madencilik havuzu denilen bilgisayar ağları kullanılmaktadır. Kısacası birden fazla bilgisayarın bir araya getirilip bir ağ oluşturulması ve yüksek performans elde edilmeye çalışılmaktadır. Sonuç olarak bir ortaklık söz konusu olduğu için kazanılan ödülde paylaşılmaktadır. Madenciler sistemde bulacak blok yani bitcoin kalmadığı zaman elde edeceği gelirleri para transferleri sayesinde devam edeceği düşünülmektedir (Eyal vd., 2016)

\section{Ethereum}

Bu para biriminin merkezi isviçredir. Ethereum Foundation geliştirmiştir. $\mathrm{Bu}$ platformun akıllı zeki sözleşmeleri yoktur. Kendisine ait Turing Complete1 program dilini kullanır. Bu platformda engel veya sıkıntı yaratacak dolandırıcılık üçüncü taraf müdahalesi dolandırıcılık gibi eylemler olmadan programlandığ 1 şekilde işevini devam ettirir. Bu platformda blockchain üzerinden çalışmaktadır. Güçlü bir Küresel altyapısı bulunmaktadır. Kayıt alınan bilgiler fonlar aracı veya karşı tarafın riski olmadan transfer edilebilmektedir. 2015 yllında piyasada yerini almaktadır. Bitcoin kadar olmasada bir çok yatırımcı tarafından rağbet görmektedir (Hileman ve Rauchs 2017, Ethereum 2018).

\section{Ripple (XRP)}

Ripple 2012 yılında piyasaya girmiştir. Bitcoin'i temel alan diğer kripto paralardan farklı olarak görülen Ripple Blockchain teknolojisi ile çalışmamaktadır. Bu özelliğinden dolayı, Ripple Bitcoin'den hemen hemen bağımsız bir yapı sergilemktedir. Merkezi değildir. fakat mutabakat protokolüne dayanmaktadır, Ripple'ın üretim ve dağıtımı Ripple Laboratuvarları aracılığı tarafından yönetilmektedir. Bu para biriminin yüz 
milyar adet arzı bulunmaktadır. Ripple'ın yüzde yirmilik kısmı Ripple firmasının kurucularının elindedir. Yüzde yirmibeşlik bölümünede Ripple Laboratuvarları sahiptir. Geriye kalan yüzde ellibeşlik kısım ise ağın büyütülmesi için dağıtım yapmak amacıyla ayrılmıştır. Bu para biriminde tüm defterler ilk andan bu yana sorunsuz bir şekilde kapatılmaktadır. Ripple ile saniyede binbeşyüz işlem gerçekleşir bu sayede ödemeler çok daha hızlıdır. Ripple genelde büyük bankalar ve diğer finans hizmet sağlayan firmalar tarafından kullanılmaka olduğı görülmektedir. Ripple çok nadir olarak diğer ticari para birimleri arasında bir köprü rolü görmek amaciyla ve gerçekleşmesi ihtimal olan sanal saldırıları önlemek maksadıyla hizmet vermektedir (Armknecht vd., 2015; Hileman ve Rauchs, 2017; Ripple, 2018).

\section{EOS.IO Yazılımı ve EOS}

EOS.IO merkezi olmayan olarak sinıflandırılan uygulamaların yatay ve dikey incelenip ölçeklendirilmesini mümkün kılmak maksadıyla Blockchain teknolojisine dahil edilerek tasarlanan bir bilgisayar yazılımıdır. Merkezi Cayman Adaları olup teknoloji yazılımı şirketi block.one tarafından oluşturulmuştur. Bu modelde, uygulamalar kendine has bir işletim sistemi benzeri olan yapılar üzerine kurulmaktadır. Bu tür yazılımlar hesapları kaydetme, hesapları doğrulama, gibi işlemleri kolaylaştırıcı eylemler yapabilmektedir. Bu nedenle, saniyede milyonları aşan işlemin gerçekleşmesini mümkün kılmakta olup, katılımcı ücretlerini ortadan kaldırmaktadır. Merkezi olarak sınıflandırılmayan uygulamaların çabuk ve kolay çalışmasını sağlamaktadır. Bu şirketin piyasaya sunduğu EOS aslında Ethereum para birimi sistemi içerisinde yer almış olan bir çeşit kripto paradır. EOS.IO yazılımınını tamamlayan şirket EOS'u sisteme geçirmiştir (Block.one).

\section{Litecoin (LTC)}

2011 yılında piyasaya girmiştir. Litecoin diğer para birimlerinden farklı olarak seksendört milyon coin limiti vardır. Charlie Lee tarafından tasarlanmıştır. Litecoin Bitcoin'den esinlenilmiş olmasına rağmen bazı farklılıkları vardır. Örneğin, Bitcoin SHA-265 yazılımn algoritmasını 
kullanır litecoin ise Scrypt yazılım algoritmasını kullanmaktadır. Ayrıca, Litecoin de Blockchain ağı üzerinde işlem yapmaktadır. Bitcoin'e nazaran daha hızlıdır; bunun yanısıra işlem maliyetleri ise daha azdır. Kullanılan algoritma sebebiyle üretim maliyetleri diğer para birimlerine nazaran fazladır (Gibbs veYordchim, 2014).

\section{Kripto Paralarin Muhasebesi}

Muhasebe içinde barındırdığı kavramsal çerçeve gereği yapılan her işelemde olması gerektiği gibi sanal kripto paralarda da tarafsız ve eksik olamyan bilgiyi bilgi kullanıcılaraina sunmakla sorumludur. Bu maddi değeri olan paranın işletmesi kaydedilmesi gerekmektedir. (Raiborn ve Sivitanides, 2015, s.33). Bazı ülkelerde olmasına karşın ülkemizde kripto para kullanıcıları için hazırlanmış yasal bir mevzuat bulunmamaktadır. Kısacası bu paralarla nasıl ödeme nasıl tahsilat yapılacağını anlatan bir yasal bir yönerge bulunmamaktadır. Para Yapısal olarak ödeme, tahsilat ve bir takım işlevlere aracı olduğu Kabul edilmektedir. Kısacası bu paraların nasıl muhasebeleştirileceği konusunda bu paraların nasıl kullanıldığıdı dikkate alınmalıdır. Ödeme aracı olarak düşünülürse 10 Hazır Değerler grubu altında yeni bir alt hesap açılması düşülebilir. Burada devreye giren fonksiyon şüphesiz özün önceliği kavramıdır. Bu tür paraların değerinin artıp eksildiği kendine has bir borsası olduğu düşünülürse yabancı paraların muhasebeleştirilmesi gibi kayıt altına alınabilmektedir. Bu durumda 100 kasa hesabının altın kripto para kasası gibi bir hesap açlabilmektedir. Yabancı paralarda görülen kur artışı azalışında oluşan kıymet artış ya da azalışlarında kullanılan 646 ve 656 numaralı kambiyo karı ya da kambiyo zararı hesabı üzerinde muhasebe kayıtlarına aktarılmaktadır. Kripto paraların transferi alımı satımı gibi konularda oluşan harcamalar masraflar 653 Komisyon Giderleri Hesabında izlenebilmektedir. Türkiye Muhasebe standartları bu paraların muhasebesi için (TMS) 21 Yabancı Paralı İşlemlerin Muhasebeleştirilmesi Standardını kullanmayı öngörmektedir. Bu standard bu paralar için spot kur uygulanmasını söylemiş ama bu kurun hangi kur olduğunu belirtememiştir (Örten vd., 2014, s.331). Genelde yapılan uygulama ise bu kripto paraların türkiyede faaliyet gösteren bir borsası olmadığı için Merkez bankası kurunu kullanmaktadır. 
Örnek1: Firma 05.03.2019 tarihinde elindeki kaynağ1 değerlendirmek amacıyla 10 Bitcoin satın alıp ödeme transferini firma banka hesabından yapar. İşletme 30.05.2019 tarihinde 5 BTC'yi TL'ye çevirmiştir. 31.12.2019 tarihi itibariyle elindeki 5 bitcoini değerlemeye tabi tutmuştur

- $\quad$ 05.03.2019 tarihinde 1 Bitcoin $=43.000 \mathrm{TL}$

- $\quad$ 03.04.2019 tarihinde 1 Bitcoin $=41.000 \mathrm{TL}$

- 31.12.2019 tarihinde 1 Bitcoin $=48.000 \mathrm{TL}$

Tablo 1. Bitcoin ile yapılan işlemlerin muhasebe Kaydı

\begin{tabular}{|c|c|c|}
\hline \multicolumn{3}{|c|}{ } \\
\hline 108 DİĞER HAZIR DEĞERLER HESABI & 430.000 & \\
\hline \multicolumn{3}{|l|}{ 108.01 Kripto Paralar Hesab1 } \\
\hline \multicolumn{3}{|l|}{ 108.01.01 Bitcoin } \\
\hline 102BANKALAR HESABI & & 430.000 \\
\hline \multicolumn{3}{|c|}{ 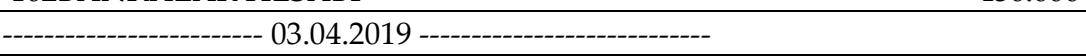 } \\
\hline 102 BANKALAR HESABI & 205000 & \\
\hline 656 KAMBIYYO ZARARLARI HESABI & 10000 & \\
\hline 108 DİĞER HAZIR DEĞERLER HS. & & 215000 \\
\hline \multicolumn{3}{|l|}{ 108.02Kripto Paralar Hesab1 } \\
\hline \multicolumn{3}{|c|}{$\begin{array}{l}108.02 .01 \text { Bitcoin } \\
\end{array}$} \\
\hline \multicolumn{3}{|c|}{ - } \\
\hline 108 DİĞER HAZIR DEĞERLER HESABI & 25.000 & \\
\hline \multicolumn{3}{|l|}{ 108.02 Kripto Paralar Hesab1 } \\
\hline \multicolumn{3}{|l|}{ 108.02.01 Bitcoin } \\
\hline 646 KAMBIYO KARLARI HESABI & & 25.000 \\
\hline $\begin{array}{l}\text { Kur Fark1 }=5 \text { Bitcoin } \times(48.000-43.000) \\
25.000 \mathrm{TL}\end{array}$ & & \\
\hline
\end{tabular}

Eğer kripto paralar türkiyede bir temti olarak olursa kabul edildiğinde VUK'un 274,275 ve 278. Maddelerine işlem yapmak etmek gerekmektedir. Emtia olarak Kabul edilen kripto paralar 157 Diğer Stoklar hesabı altında açılacak bir alt hesapta izlenebilmektedir. Tüm bunların yanı sıra emtia Kabul edilmiş olan sanal para maliyet bedeli üzerinden değerleyip kayıl altına almamız gerekmektedir. Kdv açısından bakmak gerekirse; bir malın teslimi söz konusu olmuş olduğundan KDV hesaplanması gerekmektedir (Sanal Paraların Muhasebeliştirilmesi, 2018). 
Örnek 2: A Firması yatırım amaçlı Kanada bir firmadan birimi 30.000 TL'den 5 adet bitcoin emtiası almıştır ve bitcoin'ler hemen şirketin yatırım mevduat hesabına geçmiştir. ABD firması tarafından yapılan bu işlem için herhangi bir fatura düzenlenmemiştir

Bitcoinlerin emtia olarak düşünüldügüünde yurtdışından gümrük işlemi ile geldiğini düşünerek KDV'de hesaplamalıyız.

Tablo 2. Alış Kaydı

\begin{tabular}{lcl}
\hline 157 DİĞER STOKLAR & & \\
\hline 157.01 Soyut Emtialar & 150000 & \\
\hline 191 İNDİRILECEK KDV & 27000 & 150000 \\
\hline 329 DİĞER TİCARİ BORÇLAR & & 27000 \\
\hline 360 ÖDENECEK VERGİ VE FONLAR & & \\
\hline
\end{tabular}

Daha sonra bitcoinlerin 2 adedini birim fiyatı KDV hariç 40.000 TL den Y kişisine satmıştır.

Tablo 3. Satış kaydı

\begin{tabular}{lcc}
\hline 120 ALICILAR & 94400 & \\
\hline 600 YURT İÇI SATIŞLAR & & 80000 \\
\hline 391 HESAPLANAN KDV & & 14400 \\
\hline & & \\
\hline 623 DİĞER & 94400 & \\
SATIŞLARIN MALIYETI & & 94400 \\
\hline 157 DİĞER STOKLAR & & \\
\hline
\end{tabular}

Kripto paralarla işlem yapan bir işletme yapılanişlemlerde kar etmişse bu kar gelir olduğundan dolayı kurumlar vergisinde beyan edilmelidir. Ama zarar söz konusu ise bu durumda da gerçek bir gider unsuru olarak görülmediğinden kanunen kabul edilmeyen giderler kısmında kaydedilmelidir.

\section{Sonuç}

Kripto para birimleri hakkında yapılan araştırma sonucunda bu para birimine karşı devletlerin herhangi bir yasal yükümlülük şartları taşıyan bir yönergesinin olmadığı görülmüştür. Bu durumun getireceği hukuksal 
sorumluluk çerçevesinde devletin herhangi bir yaptırım uygulamadığ1 yani devletler bu parayı tamamen yasaklamazken kullanabilirsiniz de dememektedir. Devlerin çoğunun bu para birimini tanımamaktadır. Bu para biriminin takibinin çok zor olması kanuna aykırı işlerin yapılmasına neden olmaktadır. Kısacası bu para birimini kullanarak vergi kaçırabilirsiniz rüşvet ve iltiması kolaylaştırabilirsiniz. Ayrıca bu kripto paraların vergilendirilmesi bir takım varsayımlar üzerinde yapıldığı niteliğinin tam olarak ne olduğunun anlaşılmadığı görülmektedir. Bu konyla ilgili çok fazla litaratürde bilgi olmaması olgunun anlaşılmasını zorlaştırmaktadır. Özellikle dünyada binden fazla çeşit kripto paranın olması bir borsa oluşmasına neden olmuş paraya karşı oluşan ilginin arz talep dengesi oluşturduğu ve değer artışları ve değer düşüşleri yaşanması sayesinde bir menkul kıymet gibi işlem görmesine sebep olmuştur. Litaratürde bazı kaynaklar bu paraları değerli madenlere benzetmiştir. Araştırmalarımız litaratürün muhasebe boyutu daha çok işin bu tarafını çözmeye odaklanmışken bir de kripto para oluşturma dediğimiz veri madenciliği ile elde edilen kripto paralar ile ilgili çok az bilgi bulunmaktadır. Kısacası Kripto paraların güvenirliliği konusunda tam bir güvenlik söz konusu olamamıştır. Riskin devam ettiği gözlemlenmiştir. İlgili yasal mevzuatın olmaması bir vergi kaçakçılığı rüşvet ve iltimas gibi kanunsuz işlerin yapılmasını kolaşlatırmakta olduğu görülmüştür. Yasal kapsamda bir takım düzenlemeler olmadığı takdirde yukarıda adı geçen problemli eylemlerin devam etmesi beklenip milletin menfatini zedeleyici işlemlerin yapılmasına teşvik etmektedir. Dolayısıyla en kısa zaman diliminde kripto para muhasebe kayıtları, vergilendirme esas ve hususları, bitcoin borsalarının yasal statüsü kapsamında düzenlemeler yapılmalıdır. 


\title{
EXTENDED ABSTRACT
}

\section{Crypto Money And Types, Bitcoin Case And Accounting}

\author{
Mehmet Can Yumuşaker
}

Osmaniye Korkut Ata University

The concept of money has emerged as one of the most important discoveries affecting the living standards of people who have taken part in our lives since yesterday. Especially trade has become one of the indispensable tools of shopping. The functions and effects as well as a medium of exchange money or value of an item is stand $\mathrm{d} I$ have even been counted bank loans to reserve or storage medium (Murad 1943). To qualify an asset as money, it must be portable, durable, divisible, accepted by all, and not infinite (Clayton, 2001).

Crypto $\mathrm{p}$ a ra refers to a convertible currency that requires a kind of digital signature and keys for the unspecified distribution of a non-specific sender with a math-based algorithm protected by a number of special encryption methods. It is seen that the security, assurance or accuracy of the accounts of the encrypted money is provided by a network created by people who are not aware of each other. The network maintains its network to birebir to rely on the money each encrypted with people who are not themselves manufactured the system continue to allocate a fee to determine the extent (FATF ,2014).

\section{Blockchain Technology}

This concept is a common and distributed account book tool that makes it easy to follow up the recording of transactions in a created business network. This tool can keep track of everything that has been considered to have material value and can be a shopping subject. This method reduces trade risks (Gupta , 2017). 


\section{Crypto Currency Types}

\section{What is Bitcoin}

Bitcoin, (symbol, icon: B, abbreviation: BTC) is the currency of the crypt that is not exported and trusted by an institution organization. (Sonmez, 2014, p. 8). Bitcoin is the combination of currencies that form the basis of data mining of digital money systems. This tool is used to ensure the exchange between users on the network system Bitcoin name have been masculine. ( Antonopoulos , 2014, p. 1).

The differences between bitcoin and other currencies can be explained as follows (how-bitcoinworks, 2015): a. Bitcoin is not dependent on a central authority and uses P2P3 technology. b. Bitcoin currency is completely digital. c. Bitcoin currency has an upper limit of 21 million. D. Bitcoin is a complex product. to. Bitcoin currency has a limited usage network. f. Bitcoin currency is not insured. Bitcoin currency in 2008, Satoshi Nakamoto one that is closed by an email a group was sent to the email with the launch has been made were presented to eager users. In 2009, bitcoin currency software was launched. Money swapped to the owner of money in the process, is signed for the next person money sending the dashboard of the previous trading his own crypto ie digital signature, and the next user's public key and the signature of Bitcoin is added toward the end of this business block chain used technology ( Bitcoin -article, 2014) . Bitcoin system does not have a central structure is only available in the internet environment. Therefore, as seen in other payment methods, there are almost no costs for the seller or the buyer. (What is Litecoin , 2013). There are only very small commissions as cost. In addition, security and confidentiality of all transactions are ensured thanks to the crypto technology block chain of the system (virtual currencies, 2014).

\section{Bitcoin Mining}

As it is known, the transfer of crypto currency is realized with a technology called block chain. Each process is recorded by the block chain. The transactions carried out are summarized and even reported by the block 
chain which acts as the general ledger. The information obtained is called ( hash ). Those who want to do bitcoin mining create these blocks and make the transactions happen. There are a number of protocols that must be followed for the event. These rules are clearly stated in the article created by Nakamato . It has been explained that mining can be done by establishing certain software programs with powerful machines with high power or $\mathrm{p} 2 \mathrm{p}$ technology network. The purpose of mining is to find the blocks created by the block chain. For each block, the user earns a certain fee. The system decreases the wages of miners by $50 \%$ when 210000 blocks are completed in order to provide supply balance and increases the difficulty of finding blocks. Therefore, supply increases with a decreasing acceleration. In addition, the system is designed to be 21 Million BTC (Ateş, 2016).

\section{Ethereum}

The center of this currency is Switzerland . Ethereum Foundation. This platform does not have smart clever contracts. It uses its own Turing Complete1 program language. This platform will create obstacles or adversity fraud actions such as programmable without third-party intervention, fraud business line maintains the house. It works on the platform via blockchain . It has a strong global infrastructure. Recorded information can be transferred without the risk of funds intermediary or counterparty. It is on the market in 2015. Although not as much as Bitcoin , it is in demand by many investors (Hileman and Rauchs 2017, Ethereum 2018).

\section{Ripple (XRP)}

Ripple was launched in 2012. It does not work with Ripple Blockchain technology, which is seen as different from other crypto coins based on Bitcoin. Due to this feature, Ripple is almost independent of Bitcoin . It is not central . but based on the agreement protocol, Ripple's production and distribution is managed by Ripple Laboratories . 


\section{EOS.IO Software and EOS}

EOS.IO is computer software designed to incorporate Blockchain technology to enable horizontal and vertical review and scaling of applications classified as decentralized. Headquartered in Cayman Islands, the technology software company was created by block.one.

\section{Litecoin (LTC)}

It entered the market in 2011. Litecoin, unlike other currencies, has a limit of eighty-four million coins . Designed by Charlie Lee. Although Litecoin is inspired by Bitcoin, there are some differences. For example, Bitcoin SHA-265 algorithm uses software litecon the scrypt uses a software algorithm.

\section{Accounting of Crypto Coins}

It is responsible for providing the information users with the information that is neutral and incomplete in virtual crypto currencies as it should be in every transaction carried out in accordance with the conceptual framework it contains in accounting. The business of this monetary value must be registered. (Raiborn and Sivitanides, 2015, p. 33). Although there are some countries, there is no legal legislation for crypto currency users in our country. In short, there is no legal instruction on how to make payments with these money. Money Structurally it is considered to be a means of payment, collection and a number of functions. In short, it should be considered how these moneys are used to account for these moneys. If it is considered as a means of payment, it may be deducted to open a new sub-account under the group of 10 Cash and Cash. The function that comes into play here is of course the concept of priority of the core. Considering that this kind of money has its own stock exchange where the value of it increases or decreases, it can be recorded as accounting of foreign currencies. In this case, an account such as a gold crypto money box of 100 cash accounts can be opened. Foreign currency gains and losses arising from the decrease or increase in foreign exchange rates are recorded in the accounting records on foreign currency gain or loss 
account 646 and 656. Expenses incurred in matters such as transfer, purchase and sale of crypto currencies can be tracked in the Costs 653 Commission Expenses Account. Turkey accounting standards for the accounting of these funds (IAS) 21, Accounting for Foreign Currency Transactions envisages using the standard. This Standard states that a spot exchange rate should be applied for these currencies, but it is not possible to determine which exchange rate (Örten vd., 2014, p.331).

\section{Kaynakça / References}

Ateş, B. A. (2016). Kripto para birimleri, bitcoin ve muhasebesi. Journal of Institute of Social Sciences, 7, 349-366.

Ali, R., Barrdear, J., Clews, R. ve Southgate, J. (2014a). The economics of digital currencies. Bank Of England Quarterly Bulletin, 3, 1- 13.

Armknecht, F., Karame, G. O., Mandal, A., Youssef, F., ve Zenner, E. (2015). Ripple: Overview and outlook. In International Conference on Trust and Trustworthy Computing (p. 163-180), Cham:Springer.

Boyes, W. ve Melvin, M. (2013). Ekonominin temelleri. (5. Bsm) (E. Telatar çev.), Ankara:Nobel Yayıncılık.

Block.one. Frequently Asked Questions-Here are some common questions about EOS and EOS.IO. Erişim tarihi: 27 Nisan 2018. Alınan yer https://eos.io/faq

Clayton, G. E. (2001).Economics:Principles and practices. Glencoe:McGrawHill.

Çağlar, Ü. (2007). Elektronik para: Enformasyon teknolojisindeki gelişmeler ve yeni ödeme sistemleri. Sosyal Bilimler Dergisi, 17, 177186.

Erdem, E.(2008). Para banka ve finansal sistem. (2.Bsm), Ankara:Detay Yayıncilik.

Ethereum (2018). Build unstoppable applications. 22 Şubat 2018 tarihinde https://www.ethereum.org/adresinden erişilmiştir. 
The Federal Reserve Bank of Philadelphia (2013). Functions and characteristics of money. 10 Şubat 2018 tarihinde https://www.philadelphiafed.org/education/teachers/resources/fedtoday/Functions and Characteristics of Money Lesson.pdf adresinden erişilmiştir.

Force, F. A. T. (2014). Virtual currencies: Key definitions and potential AML/CFT risks. FATF Report.

Gibbs, T. ve Yordchim, S. (2014). Thai perception on litecoin value. World Academy of Science, Engineering and Technology, International Journal of Social, Behavioral, Educational, Economic, Business and Industrial Engineering, 8(8), 2626-2628.

Gupta, M. (2017). Blockchain for dummies. New Jersey: John Wiley \& Sons,Inc.

Hileman, G. ve Rauchs, M. (2017). Global cryptocurrency Benchmarking study. Cambridge:Cambridge Centre for Alternative Finance.

Örten, R., Kaval, H. ve Karapinar, A. (2013). Türkiye muhasebe finansal raporlama standartlar uygulama ve yorumları. (7. Bsk) Ankara:Gazi Kitabevi

Özatay, F. (2011). Parasal iktisat kuram ve politika. Ankara:Efil Yayınevi,

Nakamoto, S.(2008). Bitcoin: A Peer-to-peer electronic cash system. 24.02.2018 tarihinde http://www.bitcoin.org/bitcoin.pdf adresinden erişilmiştir.

Murad, A. (1943). The nature of money. Southern Economic Journal, 9(3),217-233.

Raiborn, C. ve Sivitanides, M. (2015). Accounting issues related to bitcoins. The Journal of Corporate Accounting Finance, 2, 25-34.

Sönmez, A.(2014), Sanal para bitcoin, The Turkish Online Journal of Design, Art and Communication - TOJDAC, 4(3), 1-14.

Şener, O.H. (2007). Elektronik paranın (nakdi) para kavramı bakımından değerlendirilmesi, Dokuz Eylül Üniversitesi Hukuk Fakültesi Dergisi, 9(Özel Sayı), 455-490.

Yalçin, N. ve Gürbüz, F. (2015). Açık kaynak para birimi bitcoin. Akademik Bilişim 2015, http://ab.org.tr/ab15/bildiri/435.pdf adresinden erişilmiştir. 
Yilmaz, Y., (2007). Kriptoloji uygulamalarında hukuki boyut. Marmara Üniversitesi Hukuk Fakültesi Hukuk Araştırmaları Dergisi, 13(1-2), 137147.

http://www.okanacar.com/2013/12/bitcoin-btc-uygulamalar.html Okan Acar,Tarih: 28 Aralık 2013, Erişim Tarihi: 11.02.2019.

http://bitcoin-tr.com/ 10.02.2019.

https://bitcoinmagazine.com/articles/three-methods-simple-bitcoin-businessaccounting-1427833704, Marty Zigman, 11.02.2019., Erişim Tarihi:13.01.2019.

http://bortecin.com/sanal_d\%C3\%BCnyanin_gercek_parasi_bitcoin.pdf, Erişim Tarihi: 10.02.2019.

http://coin-turk.com/altcoin-nedir, Erişim Tarihi: 09.02.2019.

http://coin-turk.com/turkiyede-bitcoin-kabul-eden-yerler/ Erişim Tarihi:10.02.2019..

http://eticaretmag.com/turkiyenin-ilk-bitcoin-atmsi-istanbul/ Tarih: 2 Aralık 2013, Erişim Tarihi: 11.02.2019..

http://mfyz.com/acik-kaynak-kodlu-yazilim-nedir, Erişim Tarihi: 11.02 .2019 .

http://t24.com.tr/yazarlar/vedat-ozdan/22-soruda-bitcoin-ve-litecoinnedirne-degildir,7987 Tarih: 7 Aralık 2013, Erişim Tarihi: 11.02.2019.

http://www.bitcoinhaber.net/2014/05/bitcoin-makale.html, Erişim Tarihi: 05.02.2015.

http://www.bitcoinhaber.net/2014/12/bitcoin-cizgi-roman-oldu.html, Tarih: 13.12.2014, Erişim tarihi: 19.02.2015.

http://www.bloomberght.com/haberler/haber/1452427-bitcoin-cilginligininsonu-nereye-varacak, Tarih: 7 Kasım 2013, Erişim Tarihi: 20.02.2015.

http://www.digitalage.com.tr/makale/elektronik-para-yasal-altyapiyakavustu/, Tarih: 8.11.2013, Erişim Tarihi: 05.03.2018.

http://www.dunya.com/mt-gox-iflas-etti-220643h.htm, Dünya Tarih: 28.02. 2014, Erişim Tarihi: 01.02.2019.

http://www.dunya.com/sanal-para-birimleri-236881h.htm, Tarih: 23.08 .2014, Erişim Tarihi: 11.02.2019.

http://www.emresupcin.com/acik-kaynak-kodlu-yazilim-nedir/, Erişim Tarihi: 11.02.2019. 
http://www.milliyet.com.tr/bitcoin-turkiye-demarkette/ekonomi/detay/1980168/default.htm, Erişim Tarihi:01.02.2019. http://www.milliyet.com.tr/dijital-parayi-altinatercih/ekonomi/detay/1783529/default.htm, Erişim Erişim Tarihi: 01.02.2019. http://www.uzeldanismanlik.com/sanal-paralarin-vergilendirmesi-vemuhasebelestirilmesi/, Erişim Erişim Tarihi: 16.05.2019.

\section{Kaynakça Bilgisi / Citation Information}

Yumuşaker, M. C. (2019). Kripto para ve tipleri, bitcoin olgusu ve muhasebesi. OPUS-Uluslararası Toplum Araştırmaları Dergisi, 12 (18. UIKK Özel Sayıs1), 1007-1029. DOI: 10.26466/opus.585051. 